Article

\title{
Correlation Analysis between Different Types of Corrosion of Concrete Containing Sulfate Resisting Cement
}

\author{
Vlasta Ondrejka Harbulakova ${ }^{1, *}$, Adriana Estokova ${ }^{2}$ and Martina Kovalcikova ${ }^{2}$ \\ 1 Department of Environmental Engineering, Technical University of Kosice, Faculty of Civil Engineering, \\ Vysokoskolska 4, 04200 Kosice, Slovakia \\ 2 Faculty of Civil Engineering, Department of Material Engineering, Technical University of Kosice, \\ Vysokoskolska 4, 04200 Kosice, Slovakia; adriana.estokova@tuke.sk (A.E.); \\ martina.kovalcikova@tuke.sk (M.K.) \\ * Correspondence: vlasta.harbulakova@gmail.com; Tel.: +421-55-602-4269
}

Received: 10 May 2017; Accepted: 21 June 2017; Published: 23 June 2017

\begin{abstract}
Utilization of pozzolanic materials (fly ash, slag, zeolite, metakaolin, microsilica and more) in the manufacturing of cement and concrete has increased considerably over the last decades. Another option is to use concrete containing sulfate resisting cement. This could help minimize the harmful impacts on concrete exposed to an aggressive environment. The issue of the deteriorative impact of the three types of concrete corrosion (acidic, sulfate and leaching) investigated using correlation analysis is presented in the paper. Concentrations of silicon and calcium leached out from the concrete samples into the liquid phase and the measured $\mathrm{pH}$ values were used as input data for a mathematical approach to the study of sulfate resisting cement. The performance of sulfate resisting cement-based concrete was improved when exposed to sulfate attack, but not in the case of leaching corrosion caused by water.
\end{abstract}

Keywords: acidic corrosion; leaching; statistical analysis; sulfate corrosion

\section{Introduction}

Concrete structures are exposed to aggressive aqueous environments in very varied situations, and the range of aggressive species is wide. Numerous examples include, for example, foundation and/or parts of structures in contact with groundwater, soil or wastewater, which may be subjected to sulfate attack; and dams, water pipes and other structures exposed to the action of soft or carbonated waters that suffer leaching and/or carbonation [1]. According to the mechanisms of degradation of cementitious materials in the aggressive aqueous environment the following situations may occur:

- deterioration of concrete due to sulfate attack,

- leaching of cementitious materials by pure water,

- deterioration of concrete due to the attack of sulfuric acid, etc. Concentration of sulfates in the solution must be above minimum to result in a significant attack on concrete. The severity of sulfate attack on concrete depends on the following [2]:

- type of sulfate; magnesium and ammonium sulfates are the most-damaging to concrete;

- concentration of the sulfate; the presence of more-soluble sulfates is more damaging to concrete;

- whether the sulfate solution is stagnant of flowing; severity of attack increases in the case of flowing water;

- pressure; severity of the attack increases because pressures tend to force the sulfate solution into the concrete; 
- temperature; as with any chemical reaction, the rate of the reaction increases with temperature; and - $\quad$ presence of other ions; other ions present in the sulfate solution affect the severity of the attack.

The most effective way to prevent deteriorative changes of concrete materials is to improve the chemical composition of concrete exposed to aggressive environments. Where concrete is exposed to chemical attack from natural soils and groundwater, the exposure will be classified according to [3].

Chemical aggressive environment (XA) is divided into three classes: XA1 (slightly aggressive chemical environment), XA2 (moderately aggressive environment), and XA3 (highly aggressive environment). As sulfate leads to exposure classes XA2 and XA3, it is essential to use sulfate resisting cement to prepare the concrete. Sulfate resisting cement produced with clinker with low tricalcium aluminate content has high final compression strength, excellent processability, low bulk extensibility and excellent compatibility with a plasticizer. Lower content of tricalcium aluminate $\left(C_{3} A\right)$ in the sulfur resisting cement results in a lower content of hydrated calcium aluminates in concrete, thus limiting the formation of secondary ettringite and preventing deterioration of concrete due to sulfur attack. Cement of a slight sulfate resistance is considered to have a tricalcium aluminate $\left(\mathrm{C}_{3} \mathrm{~A}\right)$ content of less than 8 wt.\%, percentage by weight. Cement with high sulfate resistance is Portland cement, with a $\mathrm{C}_{3} \mathrm{~A}$ content less than 3.5 wt. \%.

On the other hand, a number of research studies have shown that the addition of pozzolans and industrial by-products enhances the strength and durability of mortars exposed to sulfate attack. Samples tested in [4] were manufactured with different types of cement (CEM II and sulfate resisting Portland cement) to observe the effects of the sulfate content on the mechanical behavior and dimensional stability. It was found that the presence of sulfates in recycled aggregates reduces compressive strength, and high sulfate contents can lead to dimensional instability in cement-treated granular materials. Investigation into the durability of alkali-activated slag concrete exposed to acid attack is presented in [5]. It was found that alkali-activated slag concrete of Grade 40 had a high resistance in acid environment; superior to the durability of ordinary Portland cement concrete of similar grade.

To present their findings and make the results comparable to those obtained by others, many authors use mathematical approaches to interpret the experimental results properly. Correlation analysis was used in [6] to study the relation between content and leaching of sulfates in recycled aggregates from construction and demolition wastes. Many different authors used many simulations and mathematical evaluation. Reliability is examined using survival analysis methods, including the Kaplan-Meier method, as well as regression models such as the Cox proportional hazard model, exponential regression model or normal linear regression model. Application of survival analysis in order to understand and predict failure occurrence in water supply infrastructure with the aim to develop a strategy covering the activities for pipe renovation is presented in [7].

The corrosion impacts of both sulfuric acid and chloride on the reliability index using Monte Carlo simulation are presented in [8]. Mahmoodian and Li [9] developed an analytical stochastic reliability method to predict the probability of failure of concrete sewer pipes. Analytical results obtained from the first passage theory were then verified by the Monte Carlo simulation method. A reliability-based methodology for the assessment of corrosion-affected, reinforced concrete sewers, considering serviceability and ultimate strength as limit state functions for multi-failure mode assessment, is presented in [10]. A stochastic model for system failure analysis was developed, which relates to key factors that affect concrete corrosion in a concrete sewer system in Harrogate, UK. A time-dependent Monte Carlo simulation method was employed to quantify the probability of failure of concrete sewers [6].

The aim of this paper is to present the results of the long-term experimental research of concrete corrosion due to three different aggressive media, and subsequently examine the impact of these media on concrete deterioration through the application of a mathematical approach by using correlation analysis. The most significant types of concrete deterioration, including acidic, sulfate and leaching corrosion, were taken into consideration. 


\section{Materials and Methods}

\subsection{Concrete Samples}

Concrete samples were made of sulfate resisting cement CEM I $42.5 \mathrm{~N}-\mathrm{SR} 0$ produced with clinker with a $\mathrm{C}_{3} \mathrm{~A}$ (tricalcium aluminate) content of $0 \%$. The composition of concrete mixtures based on sulfate resisting cement is presented in detail in Table 1.

Standardized concrete prisms with dimensions of $100 \times 100 \times 400 \mathrm{~mm}$ were cured for 28 days in an aqueous environment prior to testing the required mechanical parameters. The test specimens were slightly brushed in order to remove polluting particles, and dried at $105^{\circ} \mathrm{C}$ to a constant weight.

Table 1. Composition of sulfate resisting concrete mixture.

\begin{tabular}{cc}
\hline Component (units) & Amounts per $\mathbf{1} \mathbf{~ m}^{\mathbf{3}}$ of Fresh Concrete \\
\hline Sulfate resisting cement $(\mathrm{kg})$ & 360 \\
Water $(\mathrm{L})$ & 170 \\
Aggregates $0 / 4(\mathrm{~kg})$ & 825 \\
Aggregates $4 / 8(\mathrm{~kg})$ & 235 \\
Aggregates $8 / 16(\mathrm{~kg})$ & 740 \\
Plasticizer $(\mathrm{L})$ & 3.1 \\
$w / c$ coefficient & 0.47 \\
\hline
\end{tabular}

$w / c$ : Water to cement ratio.

The chemical composition of the prepared concrete samples with resisting cement was as follows: $62.57 \%$ of $\mathrm{CaO}, 22.45 \%$ of $\mathrm{SiO}_{2}, 4.53 \%$ of $\mathrm{Fe}_{2} \mathrm{O}_{3}, 2.16 \%$ of $\mathrm{Al}_{2} \mathrm{O}_{3}, 2.33 \%$ of $\mathrm{MgO}, 0.11 \%$ of $\mathrm{P}_{2} \mathrm{O}_{5}, 2.97 \%$ of $\mathrm{SO}_{3}, 0.06 \%$ of $\mathrm{Cl}, 0.2 \%$ of $\mathrm{K}_{2} \mathrm{O}, 0.14 \%$ of $\mathrm{TiO}_{2}, 2.46 \%$ others; $\mathrm{Na}_{2} \mathrm{O}$ and $\mathrm{MnO}$ were not detected.

\subsection{Corrosion Processes}

Experimental simulation of corrosion processes was focused on evaluation of the deteriorative changes caused by sulfuric acid, magnesium sulfate and tap water, and their influence on the concrete samples was prepared using sulfate resisting cement. Aggressive liquid medium was chosen to represent 3 models of deterioration processes: acidic, sulfate and leaching corrosion.

\subsubsection{Acidic Corrosion}

For the purpose of accelerated testing of the acidic attack, a solution of sulfuric acid with two different concentrations was used: 0.005 wt. \% $\mathrm{H}_{2} \mathrm{SO}_{4}(\mathrm{pH}$ value 3$)$ and 0.0005 wt. $\% \mathrm{H}_{2} \mathrm{SO}_{4}(\mathrm{pH}$ value 4). Sulfuric acid with $\mathrm{pH}=3$, marked as $\mathrm{A} 1$, represented a more concentrated solution, and sulfuric acid with $\mathrm{pH}=4$, marked as $\mathrm{A} 2$, represented a less concentrated solution. The samples of concrete composites were placed into the prepared solutions of sulfuric acid, while the volume of liquids was strictly calculated based on the volume of the immersed sample. According to the standards relating to corrosion of concrete, the ratio of the liquid solution volumes $(400-500 \mathrm{~mL})$ to the tested sample volumes was set at 10:1. The experiments were conducted in glass containers sealed with aluminium foil. The $\mathrm{pH}$ values of the sulfuric acid solutions were periodically, once a week, adjusted to level 3 and 4 , respectively.

\subsubsection{Sulfate Corrosion}

For the purpose of simulating sulfate corrosion, two chemically aggressive solutions with different concentrations of sulfate ions were used in accordance with STN 731340 [11]: an $\mathrm{MgSO}_{4}$ solution with concentration $\mathrm{c}\left(\mathrm{SO}_{4}{ }^{2-}\right)=3 \mathrm{~g} / \mathrm{L}$ (initial $\mathrm{pH}$ 8.04), marked as $\mathrm{S} 1$, and a solution with concentration $\mathrm{c}$ $\left(\mathrm{SO}_{4}{ }^{2-}\right)=10 \mathrm{~g} / \mathrm{L}$ (initial $\mathrm{pH} 8.30$ ), marked as $\mathrm{S} 2$. The experiments were conducted, similarly to the acidic experiments, in glass containers sealed with aluminium foil. The samples of cement composites were placed into the sulfate liquid medium, whose volume was calculated by determining the volume 
of the applied sample, for the whole testing period. The ratio of the volumes of the solid and liquid phases was kept at 1:10. During the experiment, the $\mathrm{pH}$ value was not adjusted at all, and its values were measured every 7 days during the laboratory experiment.

\subsubsection{Leaching}

The corrosive medium to simulate leaching corrosion was represented by tap water in accordance with the testing standards. The leaching experiment was performed in a similar way to the acidic and sulfate corrosion experiments mentioned above. The $\mathrm{pH}$ value was measured once a week without any adjustment.

The characteristics of the liquid media, with specific description and labelling for easier orientation in the following text, are given in Table 2. The parameters of corrosive media were selected in accordance with standards for concrete corrosion testing [12].

Corrosion testing through exposure of the tested concrete samples to liquid media was conducted over the period of 91 days at a laboratory temperature of $23^{\circ} \mathrm{C}$. The concentrations of $\mathrm{Ca}^{2+}$ and $\mathrm{Si}^{4+}$ ions dissolved in leachates were measured periodically, once a week, during the experiment, using X-ray fluorescence analysis (XRF).

Table 2. Corrosive media.

\begin{tabular}{ccccc}
\hline \multicolumn{2}{c}{ Liquid Medium } & Labelling & Concentration & Corrosive Characteristics \\
\hline Sulfuric acid & $\mathrm{H}_{2} \mathrm{SO}_{4}$ & $\mathrm{~A} 1$ & $0.005 \mathrm{wt.} \%$ & $\mathrm{pH}=3$ \\
Sulfuric acid & $\mathrm{H}_{2} \mathrm{SO}_{4}$ & $\mathrm{~A} 2$ & $0.0005 \mathrm{wt.} \%$ & $\mathrm{pH}=4$ \\
Magnesium sulfate & $\mathrm{MgSO}_{4}$ & $\mathrm{~S} 1$ & $0.003 \mathrm{wt} \%$ & $\mathrm{c}\left(\mathrm{SO}_{4}^{2-}\right)=3 \mathrm{~g} / \mathrm{L}$ \\
Magnesium sulfate & $\mathrm{MgSO}_{4}$ & $\mathrm{~S} 2$ & $0.01 \mathrm{wt.} \%$ & $\mathrm{c}\left(\mathrm{SO}_{4}^{2 \times}\right)=10 \mathrm{~g} / \mathrm{L}$ \\
Potable water & $\mathrm{H}_{2} \mathrm{O}$ & $\mathrm{L}$ & - & $\mathrm{pH}=7.2$ \\
\hline
\end{tabular}

wt.\%: Percentage by weight.

The leached-out amounts of $\mathrm{Ca}$ and $\mathrm{Si}$ converted to unit quantities per $1 \mathrm{~g}$ of concrete sample represented deterioration parameters used in the correlation analysis of the concrete's deterioration.

\subsection{Analytical and Statistical Methods}

A decrease of the $\mathrm{pH}$ value of concrete, along with the decrease of the alkalinity level of the concrete material, leads to its damage and cracking. Despite a broad range of methods used for measuring the $\mathrm{pH}$ of concrete, there is no standardized test procedure. Because of the important role of the $\mathrm{pH}$ with regard to the durability of concrete structures, it is highly recommended that the required measures be taken to develop a specific standard test method for measuring the $\mathrm{pH}$ of concrete with a high level of accuracy, repeatability and reproducibility [11]. In this paper, the $\mathrm{pH}$ values of the concrete leachates were determined by measuring the liquid media. The $\mathrm{pH}$ changes were measured by $\mathrm{pH}$ meter FG2-FiveGo (Mettler Toledo International Inc., Langacher Greifensee, Switzerland).

Leaching trends of silicon and calcium ions measured in each liquid phase were studied by $\mathrm{X}$-ray fluorescence analysis (XRF) using SPECTRO iQ II equipment (Ametek, Kleve, Germany) with a silicon drift detector (SDD) with a resolution of $145 \mathrm{eV}$ at 10,000 pulses. The primary beam was polarized by Bragg crystal and Highly Ordered Pyrolytic Graphite-HOPG target. The sample measurement was performed at 300 and $180 \mathrm{~s}$ at a voltage of $25 \mathrm{kV}$ with an applied current of $0.5 \mathrm{~mA}$ and $50 \mathrm{kV}$ at $1.0 \mathrm{~mA}$. The sample was flushed with helium. A calibration method of fundamental parameters for concrete leachates was used to convert the measured intensities to concentrations of elements. The measured quantities of calcium and silicon were used as input data for mathematical evaluation of the corrosion trend of concrete samples exposed to aggressive media. 
As mentioned above, a statistical method was used for evaluation of the trend of chemical element leaching, as well as for the description of a relation among the selected parameters. Information about the two-dimensional statistical data set gives a correlation coefficient $R_{x y}$ [13], as shown in Equation (1).

$$
R_{x y}=\frac{n \sum_{i=1}^{n} x_{i} y_{i}-\left(\sum_{i=1}^{n} x_{i}\right)\left(\sum_{i=1}^{n} y_{i}\right)}{\sqrt{\left[n \sum_{i=1}^{n} x_{i}^{2}-\left(\sum_{i=1}^{n} x_{i}\right)^{2}\right]\left[n \sum_{i=1}^{n} y_{i}^{2}-\left(\sum_{i=1}^{n} y_{i}\right)^{2}\right]}}
$$

The calculated $R_{\mathrm{xy}}$ values are in the interval $<-1,1>$. If $R_{\mathrm{xy}}=1$, the correlation is full linear; if $R_{\mathrm{xy}}=-1$, then the correlation is inversely linear; and if $R_{\mathrm{xy}}=0$, the pairs of values are fully independent. Then, degree of the correlative closeness is defined as: medium, if $0.3 \leq\left|R_{\mathrm{xy}}\right|<0.5$; significant, if $0.5 \leq\left|R_{\mathrm{xy}}\right|<0.7$; high, if $0.7 \leq\left|R_{\mathrm{xy}}\right|<0.9$; and very high, if $0.9 \leq\left|R_{\mathrm{xy}}\right|$. A high correlation means that two or more variables have a strong relationship with each other, while a low correlation means that the variables are hardly related. For the purposes of our assessment, the correlation coefficient was obtained using the function "Pearson" in Microsoft Excel.

\section{Results and Discussion}

The results of correlation analysis are presented and discussed separately for each type of corrosion.

\subsection{Acidic Corrosion}

The $\mathrm{pH}$ is an important parameter for indicating the alkalinity level of concrete. The $\mathrm{pH}$ of concrete decreases because of the penetration of the aggressive ions under the influence of aggressive media, thereby dissolving the alkali compounds. This is documented by the increase in the $\mathrm{pH}$ of all liquid media.

Concentrations of calcium and silicon in sulfuric acid solutions (of different concentrations) as a function of $\mathrm{pH}$ are given in Figures 1-4.

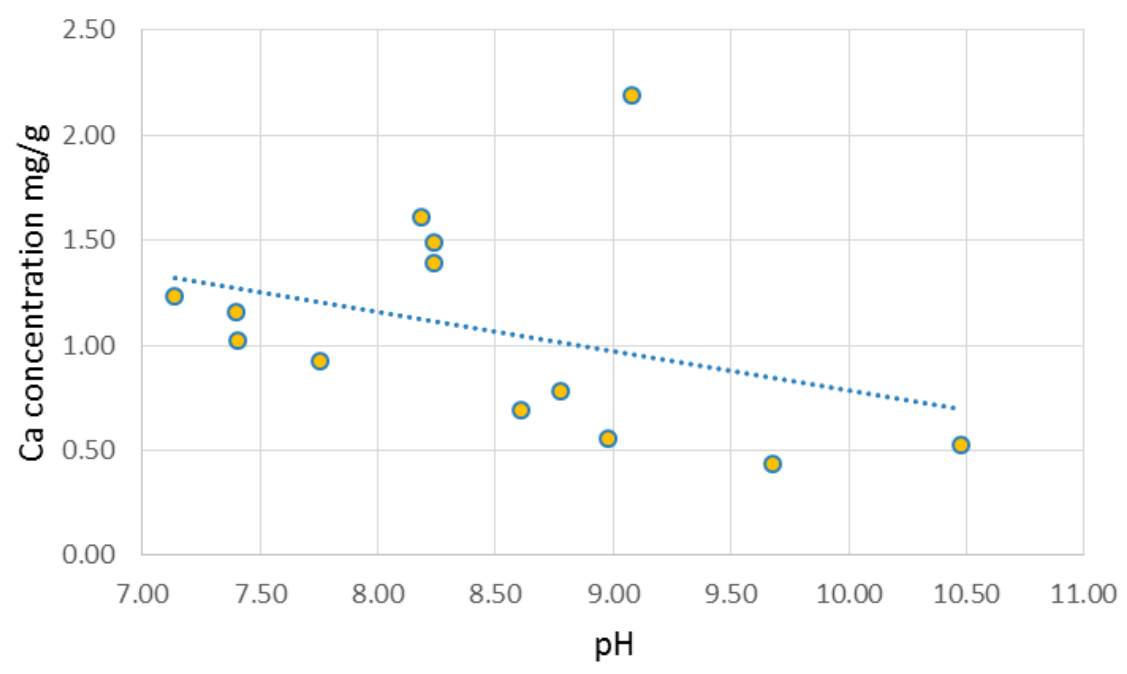

Figure 1. Curves $\mathrm{Ca}=\mathrm{f}(\mathrm{pH})$ in sulfuric acid (A1). 


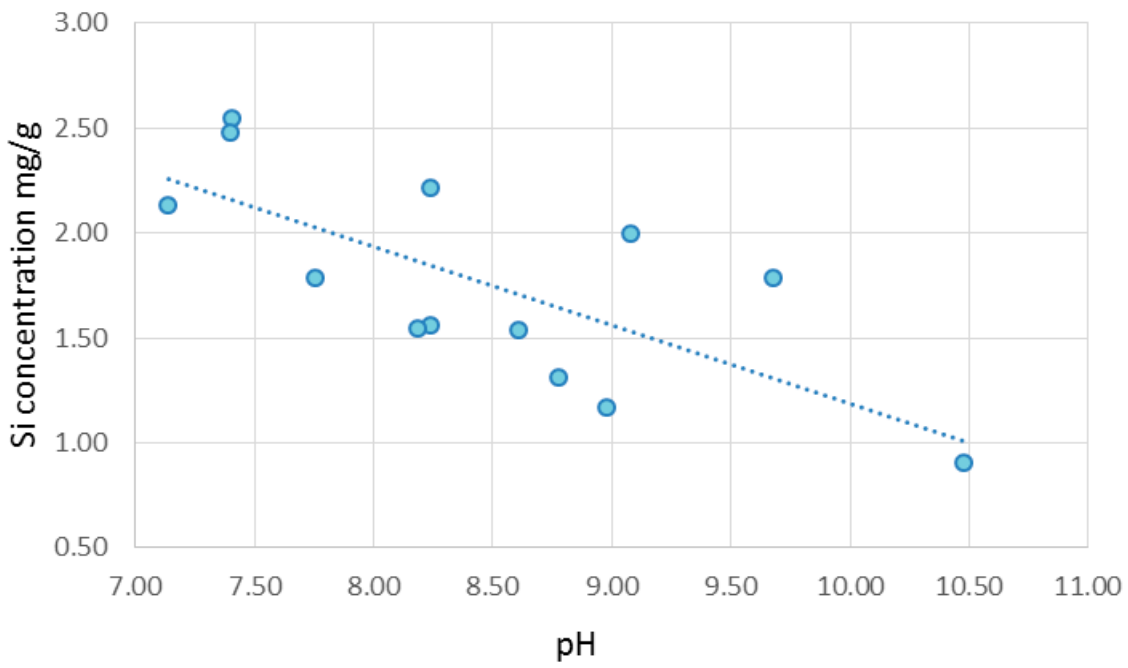

Figure 2. Curve $\mathrm{Si}=\mathrm{f}(\mathrm{pH})$ in sulfuric acid (A1).

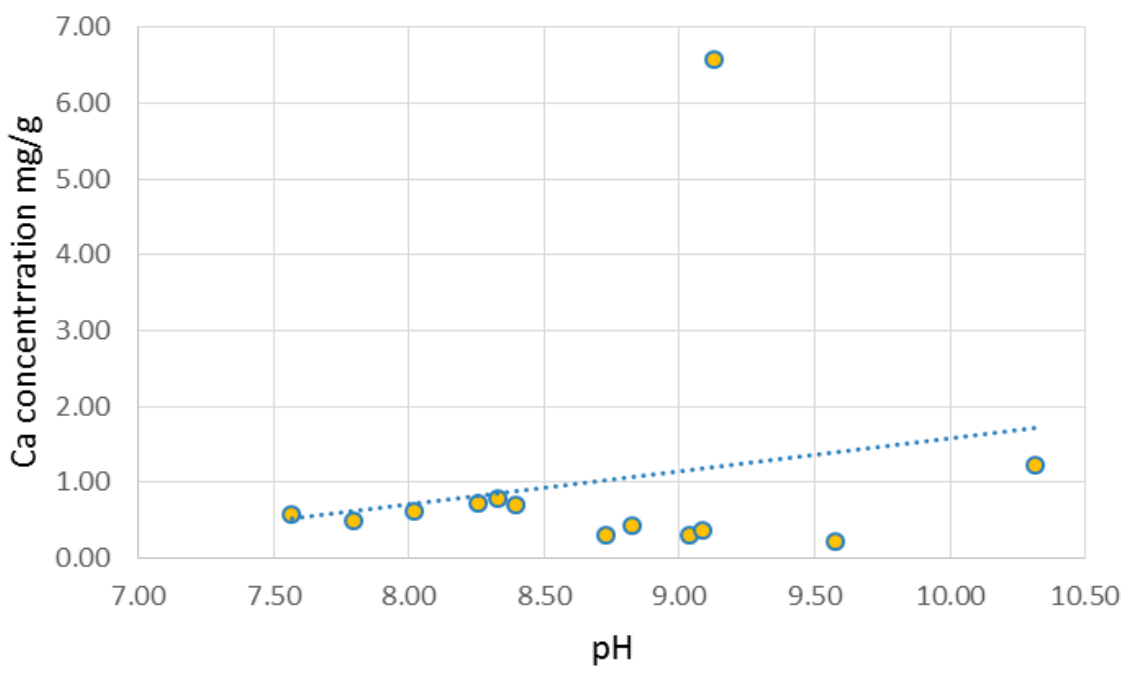

Figure 3. Curve $\mathrm{Ca}=\mathrm{f}(\mathrm{pH})$ in sulfuric acid (A2).

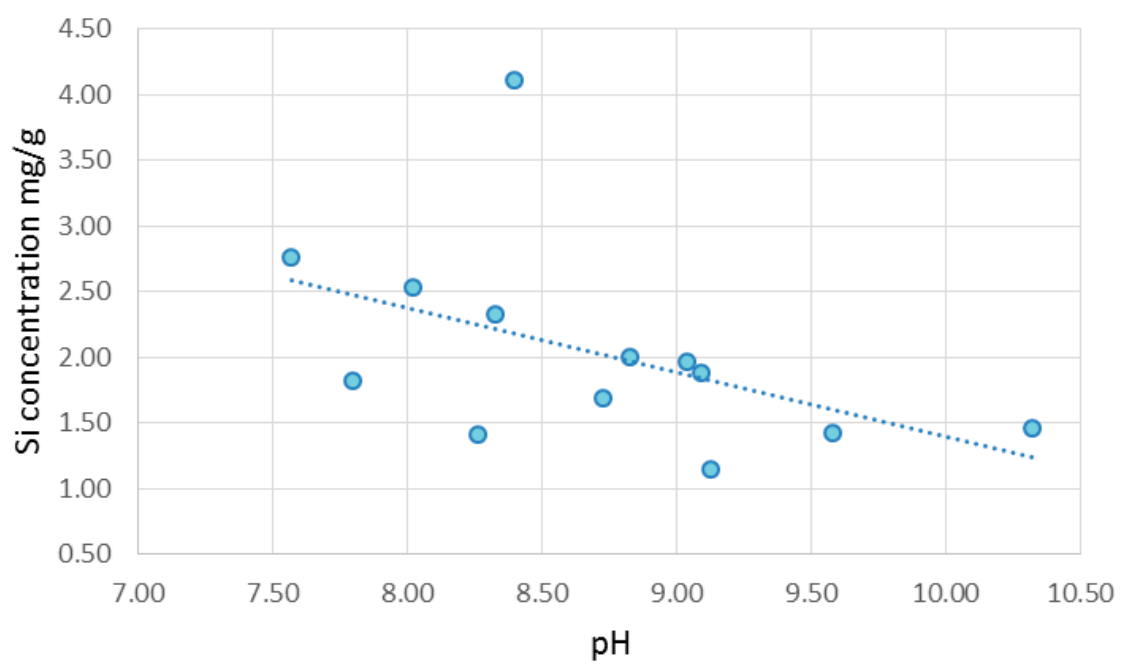

Figure 4. Curve $\mathrm{Si}=\mathrm{f}(\mathrm{pH})$ in sulfuric acid (A2). 
As shown in Figures 1-4, the statistical group consisted of 13 values representing the input data to compute the correlation coefficients. All the measured values were included in the calculation.

The dependency of $\mathrm{pH}$ gradients of sulfuric acid solutions of different concentrations during the experiments $\mathrm{pH}(\mathrm{A} 1)=\mathrm{f}(\mathrm{pH}(\mathrm{A} 2)$ is given in Figure 5.

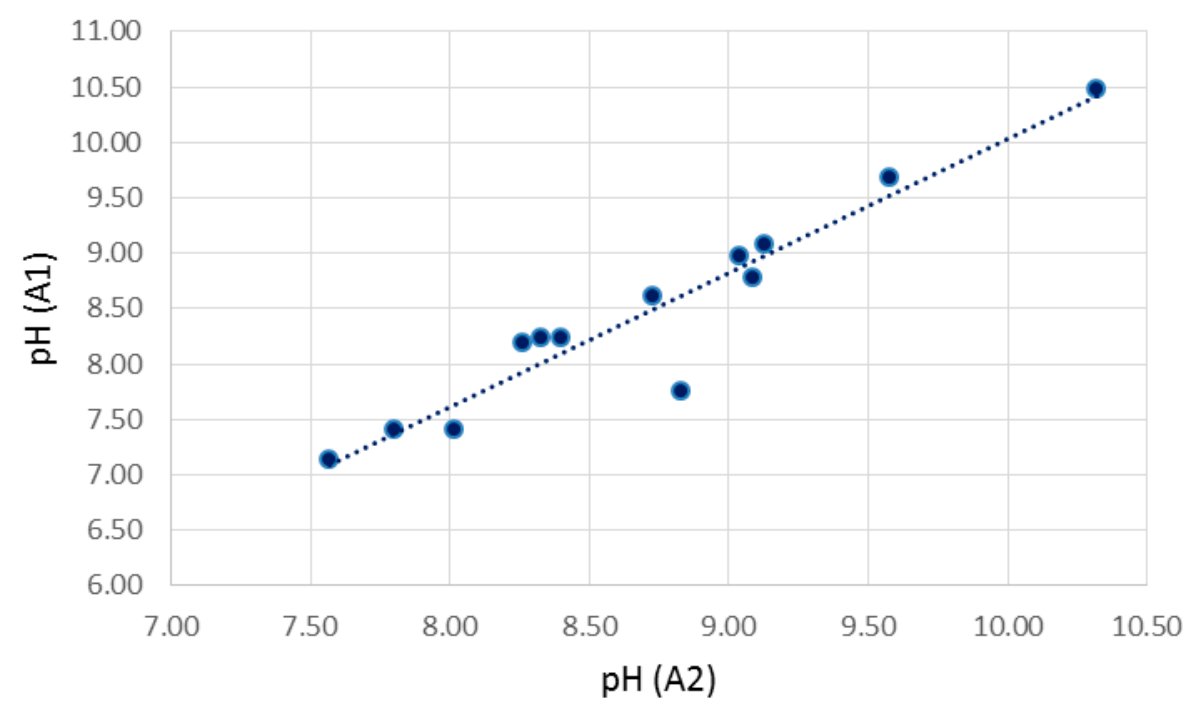

Figure 5. Dependency $\mathrm{pH}(\mathrm{A} 2)=\mathrm{f}(\mathrm{pH}(\mathrm{A} 1))$.

Correlations between leached-out amounts of calcium or silicon as main components of the cement matrix and changes in the $\mathrm{pH}$ values of the sulfuric acid solutions according to different concentrations are given in Table 3.

Table 3. Correlation between leached-out $\mathrm{Ca}$ and Si ions, respectively, and $\mathrm{pH}$ of acid media.

\begin{tabular}{cccccc}
\hline Sulfuric Acid & \multicolumn{2}{c}{ A1 } & \multicolumn{2}{c}{ A2 } & pH \\
\hline Correlated parameters & $\mathrm{Ca} / \mathrm{pH}$ & $\mathrm{Si} / \mathrm{pH}$ & $\mathrm{Ca} / \mathrm{pH}$ & $\mathrm{Si} / \mathrm{pH}$ & $\mathrm{pH}(\mathrm{A} 1) / \mathrm{pH}(\mathrm{A} 2)$ \\
$R_{\mathrm{xy}}$ & -0.35 & -0.72 & 0.20 & -0.48 & 0.95 \\
\hline
\end{tabular}

No significant correlation was found between leached-out masses of calcium and the increase of the $\mathrm{pH}$ in acidic media. This could point to the fact that not only calcium compounds were responsible for the $\mathrm{pH}$ increase. An inverse correlation was observed for silicon dissolving, which means that the more silicon was dissolved, the lower the $\mathrm{pH}$ value in the leachate. This confirms the mechanism of sulfuric acid attack on concrete.

The first step in acidic corrosion by $\mathrm{H}_{2} \mathrm{SO}_{4}$ is linked to formation of calcium sulfate through a chemical reaction of sulfuric acid with calcium hydroxide $\left(\mathrm{Ca}(\mathrm{OH})_{2}\right)$-Equation (2) - and C-S-H phase $\left(x \mathrm{CaO} \cdot \mathrm{SiO}_{2} \times \mathrm{aq}\right)$ and its sub-sequent conversion to amorphous silica [14] according to Equation (3).

$$
\begin{gathered}
\mathrm{Ca}(\mathrm{OH})_{2}+\mathrm{H}_{2} \mathrm{SO}_{4} \rightarrow \mathrm{CaSO}_{4} \cdot 2 \mathrm{H}_{2} \mathrm{O} \\
x \mathrm{CaO} \cdot \mathrm{SiO}_{2} \times \mathrm{aq}+x \mathrm{H}_{2} \mathrm{SO}_{4}+x \mathrm{H}_{2} \mathrm{O} \rightarrow x \mathrm{CaSO}_{4} \times 2 \mathrm{H}_{2} \mathrm{O}+\mathrm{SiO}_{2} \times \mathrm{aq}
\end{gathered}
$$

Amorphous silica is soluble, and in the normal pH-range (4-9) the major dissolved species is $\mathrm{H}_{4} \mathrm{SiO}_{4}$, according to Equation (4) [15].

$$
\mathrm{SiO}_{2}(\mathrm{~s})+2 \mathrm{H}_{2} \mathrm{O} \rightarrow \mathrm{H}_{4} \mathrm{SiO}_{4}
$$

A strong correlation with very high correlation closeness was expected between $\mathrm{Ca}$ leached-out masses, due to $\mathrm{H}_{2} \mathrm{SO}_{4}$ of different concentrations. However, as seen in Table 4, the correlation 
coefficient was calculated to be equal to 0.69 , which means only significant closeness. This proves that calcium compounds do not have the same leaching rate over the testing period in $\mathrm{H}_{2} \mathrm{SO}_{4}$ with different concentrations. These results are in accordance with Živica [16], Myiamoto [17], Colombani [18] and Gay [19], who reported that the degradation mainly concerned Portlandite, rather than C-S-H phase when concrete was exposed to acid attack.

Table 4. Correlation between $\mathrm{Ca}(\mathrm{Si})$ leached-out masses due to $\mathrm{H}_{2} \mathrm{SO}_{4}$ of different concentrations.

\begin{tabular}{ccc}
\hline Element & Ca & Si \\
\hline Correlated samples & A1/A2 & A1/A2 \\
$R_{x y}$ & 0.69 & 0.43 \\
\hline
\end{tabular}

An even lower correlation closeness with the correlation coefficient $R_{\mathrm{xy}}=0.43$ was found for silicon dissolving due to different concentrations of $\mathrm{H}_{2} \mathrm{SO}_{4}$. These findings did not confirm similar leaching mechanisms and consequent behavior of calcium or silicon in the acidic leachates during the experiment. This is in accordance with Miyamoto [17], who reported that the deterioration mechanism of concrete caused by sulfuric acid was different for high and low concentrations.

In addition, differences in leaching rates were much more visible when comparing the correlation coefficients of $\mathrm{Ca} / \mathrm{Si}$ leaching (Table 5). While in $\mathrm{H}_{2} \mathrm{SO}_{4}$ with $\mathrm{pH}=3$ (A1) a medium linear correlation was found between calcium and silicon leaching over a testing experimental period, an inverse correlation was calculated for the elements in $\mathrm{H}_{2} \mathrm{SO}_{4}$ with $\mathrm{pH}=4$ (A2).

Table 5. Correlation between leached-out $\mathrm{Ca}$ and $\mathrm{Si}$ ions in acidic media.

\begin{tabular}{ccc}
\hline Sulfuric Acid & A1 & \multicolumn{2}{c}{ A2 } \\
\hline Correlated parameters & \multicolumn{2}{c}{$\mathrm{Ca} / \mathrm{Si}$} \\
$R_{\mathrm{xy}}$ & 0.42 & -0.32 \\
\hline
\end{tabular}

The calculated low dependency can be due to the fact that, after leaching, calcium ions participating in chemical reactions in the leachate result in the formation of new sulfate compounds such as gypsum or ettringite which precipitate on the concrete surface as mentioned in [20].

\subsection{Sulfate Corrosion}

Concentrations of calcium and silicon in solutions as a function of $\mathrm{pH}$ are given in Figures 6-9.

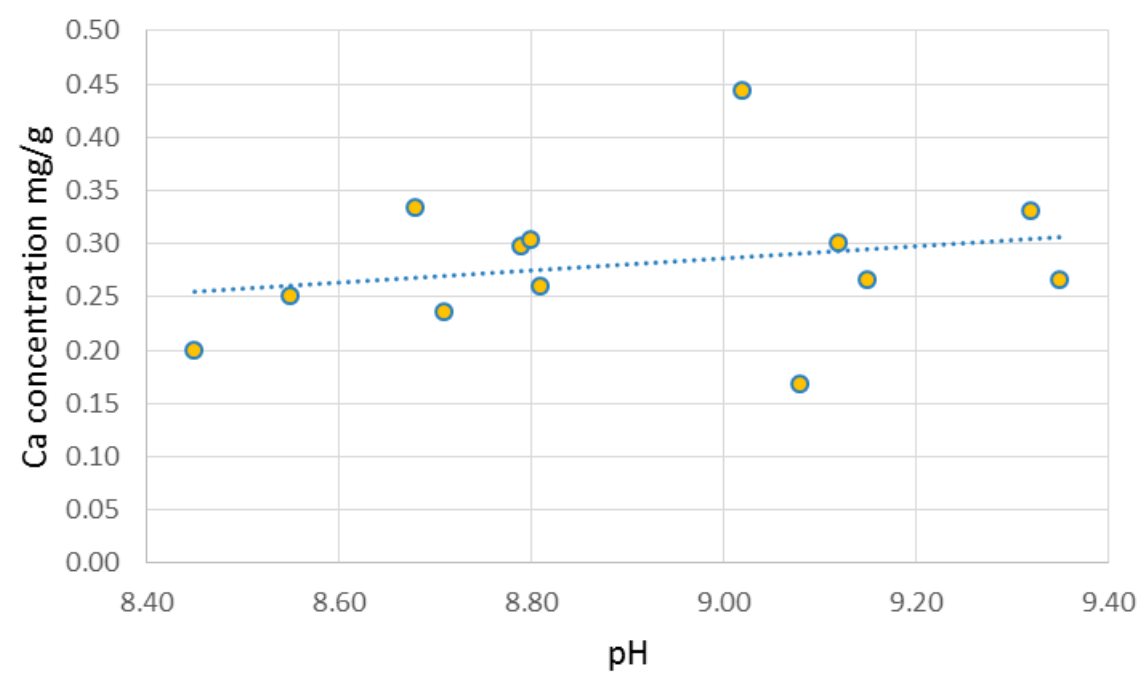

Figure 6. Curve $\mathrm{Ca}=\mathrm{f}(\mathrm{pH})$ in magnesium sulfate (S1). 


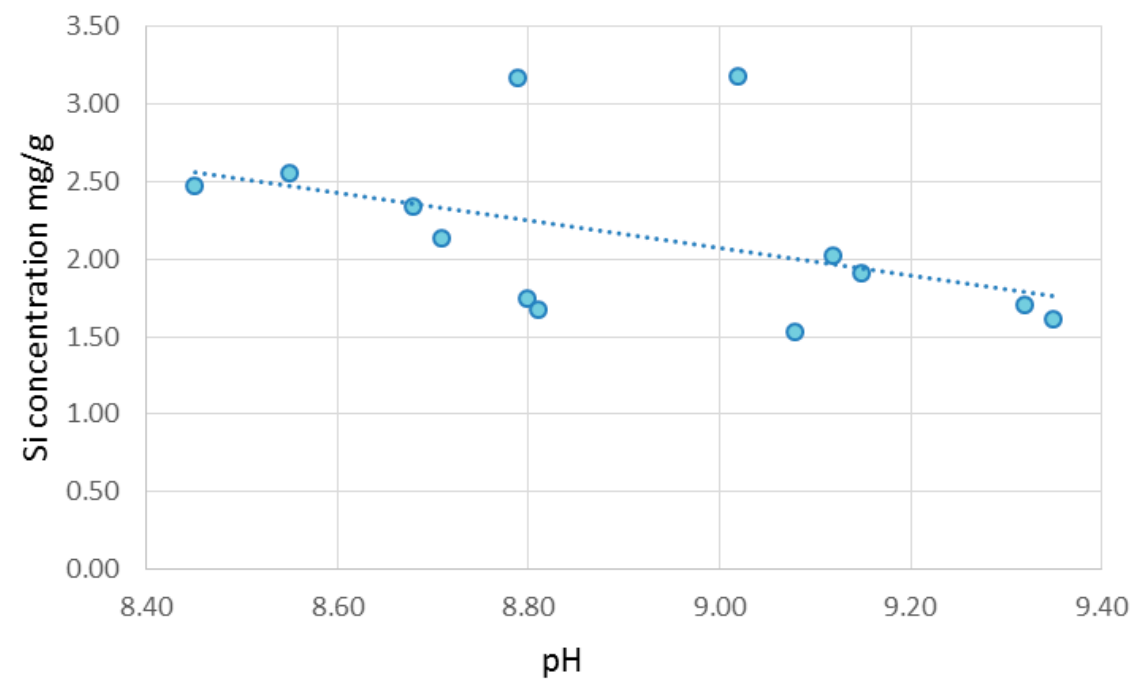

Figure 7. Curve $\mathrm{Si}=\mathrm{f}(\mathrm{pH})$ in magnesium sulfate (S1).

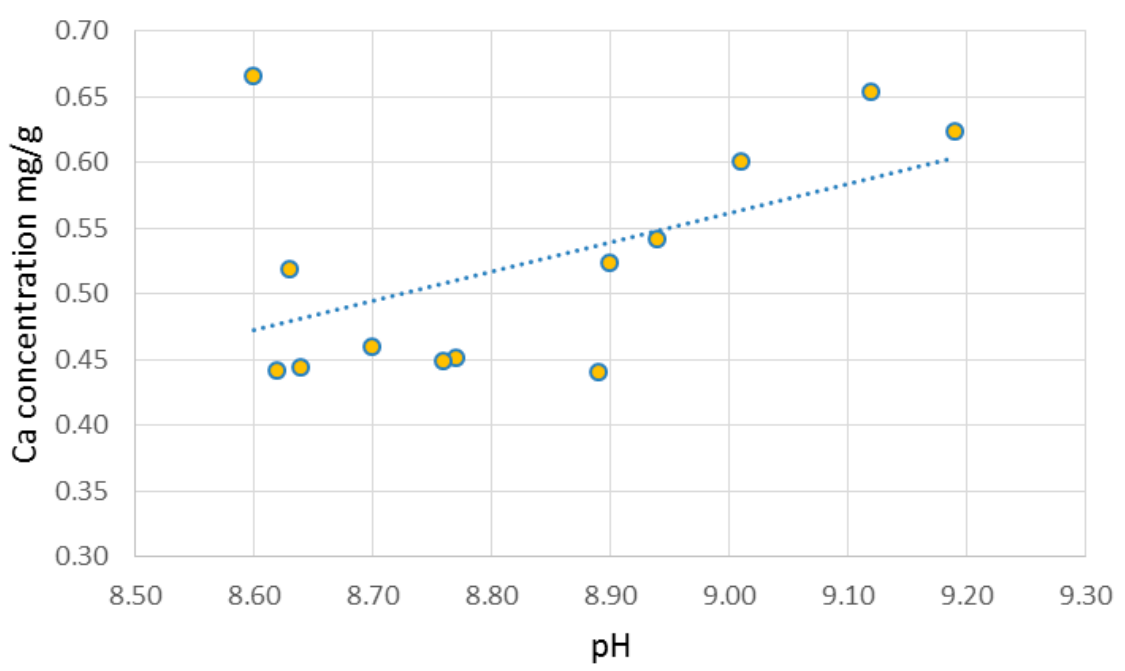

Figure 8. Curve $\mathrm{Ca}=\mathrm{f}(\mathrm{pH})$ in magnesium sulfate (S2).

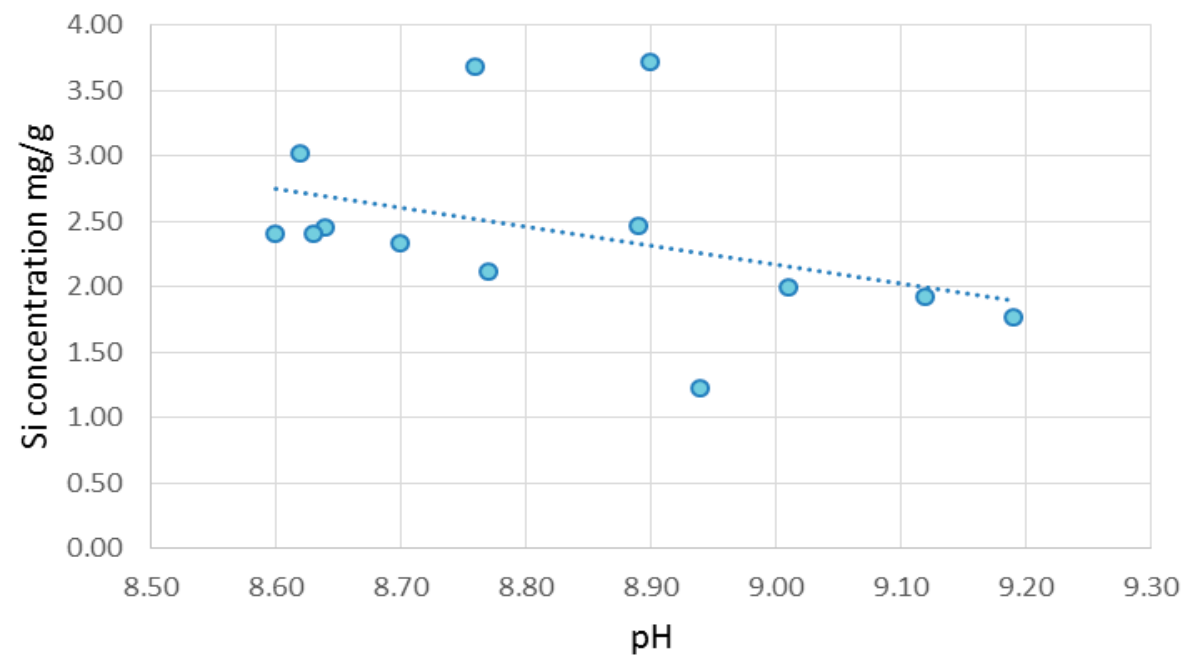

Figure 9. Curve $\mathrm{Si}=\mathrm{f}(\mathrm{pH})$ in magnesium sulfate (S2). 
Dependency of $\mathrm{pH}$ gradients of manganese sulfate solutions of different concentrations during the experiments $\mathrm{pH}(\mathrm{S} 1)=\mathrm{f}(\mathrm{pH}(\mathrm{S} 2))$ is given in Figure 10 .

The correlation coefficients of dependency between leached-out $\mathrm{Ca}$ and $\mathrm{Si}$ ions, respectively, and $\mathrm{pH}$ of magnesium sulfate solution are given in Table 6.

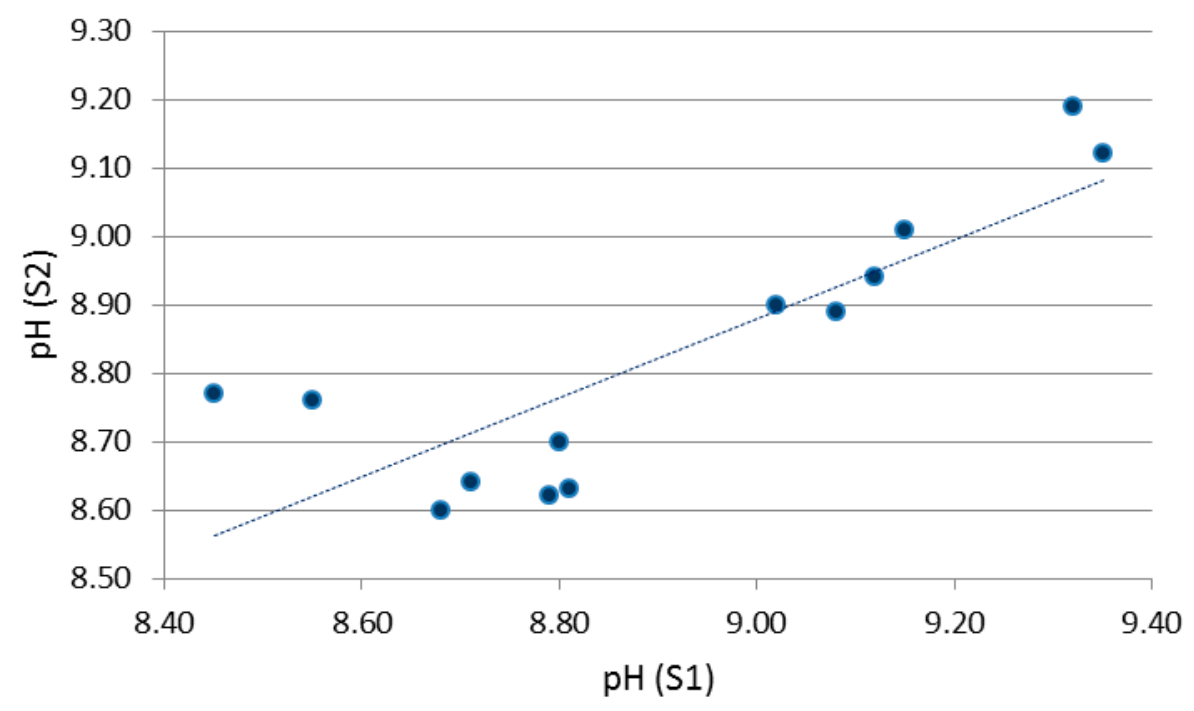

Figure 10. Dependency $\mathrm{pH}(\mathrm{S} 1)=\mathrm{f}(\mathrm{pH}(\mathrm{S} 2))$.

Table 6. Correlation between leached-out $\mathrm{Ca}$ and $\mathrm{Si}$ ions, respectively, and $\mathrm{pH}$ of magnesium sulfate solution.

\begin{tabular}{cccccc}
\hline $\mathbf{M g S O}_{4}$ Solution & \multicolumn{2}{c}{$\mathbf{S 1}$} & \multicolumn{2}{c}{ S2 } & pH \\
\hline Correlated parameters & $\mathrm{Ca} / \mathrm{pH}$ & $\mathrm{Si} / \mathrm{pH}$ & $\mathrm{Ca} / \mathrm{pH}$ & $\mathrm{Si} / \mathrm{pH}$ & $\mathrm{pH}(\mathrm{S} 1 / \mathrm{S} 2)$ \\
$R_{\mathrm{xy}}$ & 0.24 & -0.45 & 0.51 & -0.40 & 0.84 \\
\hline
\end{tabular}

Similar to the analysis of acidic corrosion, no significant correlation between leached-out masses of calcium and the increase of $\mathrm{pH}$ in magnesium sulfate solutions was found during the experiment. This is contrary to the results of slag-based concrete composites, which were studied in [21], where a strong correlation for $\mathrm{Ca} / \mathrm{pH}$ leaching was found. The difference in the finding was probably due to the different chemical composition of the analyzed concrete. Thus, the main chemical reaction of concrete deterioration affected by magnesium sulfate, resulting in the formation of magnesium hydroxide-Equation (5)—was not confirmed.

$$
\mathrm{Mg}^{2+}+\mathrm{SO}_{4}{ }^{2-}+\mathrm{Ca}(\mathrm{OH})_{2}+2 \mathrm{H}_{2} \mathrm{O} \rightarrow \mathrm{Mg}(\mathrm{OH})_{2}+\mathrm{CaSO}_{4} \cdot 2 \mathrm{H}_{2} \mathrm{O}
$$

Based on the calculated correlation coefficients (Table 7), medium correlation for calcium and significant correlation for silicon were observed during the experiment in case of the magnesium sulfate solutions of different concentrations.

Table 7. Correlation between leached-out $\mathrm{Ca}$ and $\mathrm{Si}$ ions, respectively, and $\mathrm{pH}$ of magnesium sulfate solution.

\begin{tabular}{ccc}
\hline Element & Ca & Si \\
\hline Correlated samples & $\mathrm{S} 1 / \mathrm{S} 2$ & $\mathrm{~S} 1 / \mathrm{S} 2$ \\
$R_{\mathrm{xy}}$ & 0.40 & 0.64 \\
\hline
\end{tabular}


Surprisingly, a high correlation with a correlation coefficient equal to 0.72 was found (Table 8) between leaching rates of calcium and silicon in magnesium sulfate and a sulfate ion concentration of 3 $\mathrm{g} / \mathrm{L}$ (S1). However, the results for leaching rates in magnesium sulfate with a sulfate ion concentration of $10 \mathrm{~g} / \mathrm{L}$ (S2) were found to be totally different. Comparing the leaching rates during the experimental period, an inverse correlation was calculated. The findings revealed that, in spite of the leaching medium having the same chemical composition, the leaching mechanisms of the analyzed compounds of calcium or silicon were not the same. The findings could be connected with a different behavior of calcium in the $\mathrm{MgSO}_{4}$ media. A higher sulfate ion concentration of $10 \mathrm{~g} / \mathrm{L}$ (S2) in the liquid medium could result in a more massive formation of calcium-based compounds precipitating on the concrete, compared to less concentrated $\mathrm{MgSO}_{4}$ solution $(3 \mathrm{~g} / \mathrm{L}$ ). Therefore, the concentration of Ca measured in the liquid could be lower than the one corresponding to the less concentrated $\mathrm{MgSO}_{4}$ solution $(3 \mathrm{~g} / \mathrm{L}$ ).

Table 8. Correlation between leached-out $\mathrm{Ca}$ and $\mathrm{Si}$ ions in magnesium sulfate solutions.

\begin{tabular}{ccc}
\hline Magnesium Sulfate & S1 & \multicolumn{2}{c}{ S2 } \\
\hline Correlated parameters & \multicolumn{2}{c}{$\mathrm{Ca} / \mathrm{Si}$} \\
$R_{\mathrm{xy}}$ & 0.47 & -0.43 \\
\hline
\end{tabular}

\subsection{Leaching}

When cement-based materials are subjected to water, even without any water pressure gradient, a leaching process is induced by calcium concentration gradients in the layer between the surface and the core of the material. Those gradients change the chemical equilibrium in the interphase, and the hydration products of concrete dissolve [22,23]. Figure 11 shows the dissolved $\mathrm{Ca}^{2+}$ versus $\mathrm{pH}$ of water during the leaching experiment.

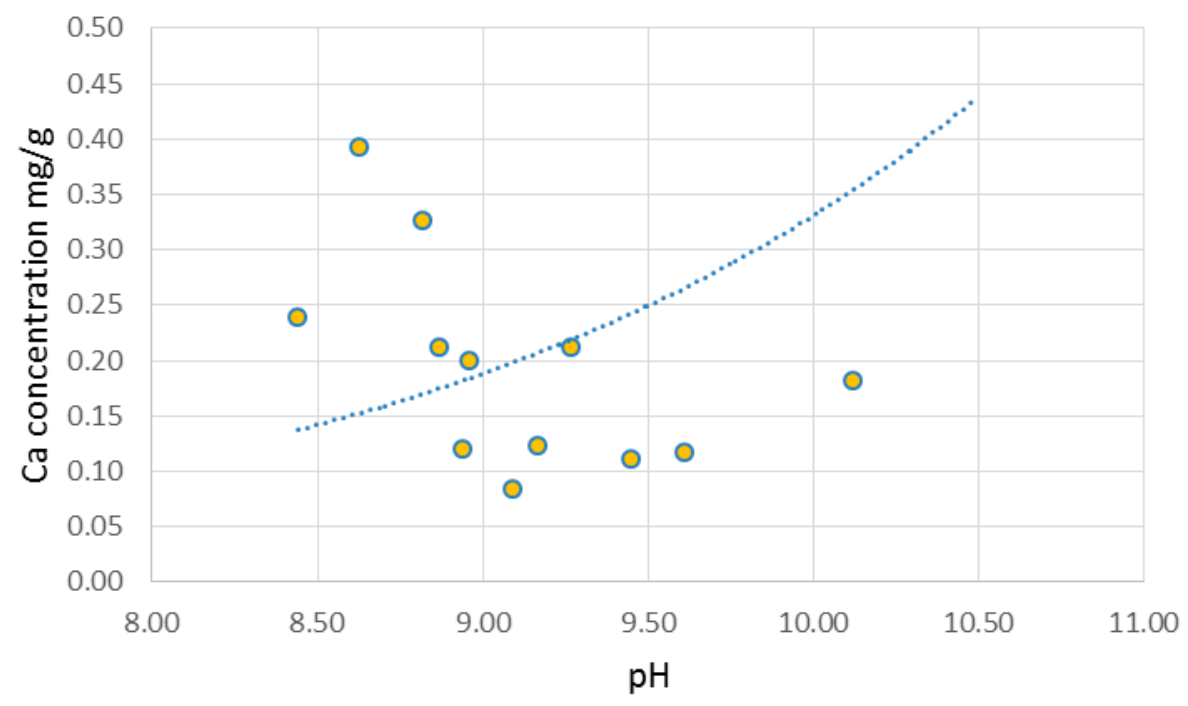

Figure 11. Curve $\mathrm{Ca}=\mathrm{f}(\mathrm{pH})$ in potable water $(\mathrm{L})$.

Dissolution and leaching of the hydration products, $\mathrm{Ca}(\mathrm{OH})_{2}$, in particular, in water results in an increase in the $\mathrm{pH}$ values of water leachate [24]. The $\mathrm{pH}$ and $\mathrm{Ca}$ concentration of water for the cement-based samples increased as the leaching period was increased in accordance with [25]. However, a linear correlation between $\mathrm{Ca}^{2+}$ and $\mathrm{pH}$ of the leaching agent could not be examined in this case. Hearn and Morley (1997) [25] found that after a certain period (56 days), the $\mathrm{pH}$ and the concentration of Ca showed a tendency to converge into a constant value, which indicated the equilibrium state of the aqueous and solid phases. Haga et al. [26] reported that the rate of leaching of 
Ca ions from Portlandite was observed to slow down after 28 days because of the lower difference in concentration gradients.

A linear correlation could be found for the relation of the amount of leached calcium to the square root of the leaching period, as presented in Roziere 2009 [27]. On the other hand, an inverse linear correlation $\left(R_{\mathrm{xy}}=-0.48\right)$ was calculated for $\mathrm{Si}$ and $\mathrm{pH}$ in potable water (Figure 12) during the experiment, similarly to in acidic and sulfate media.

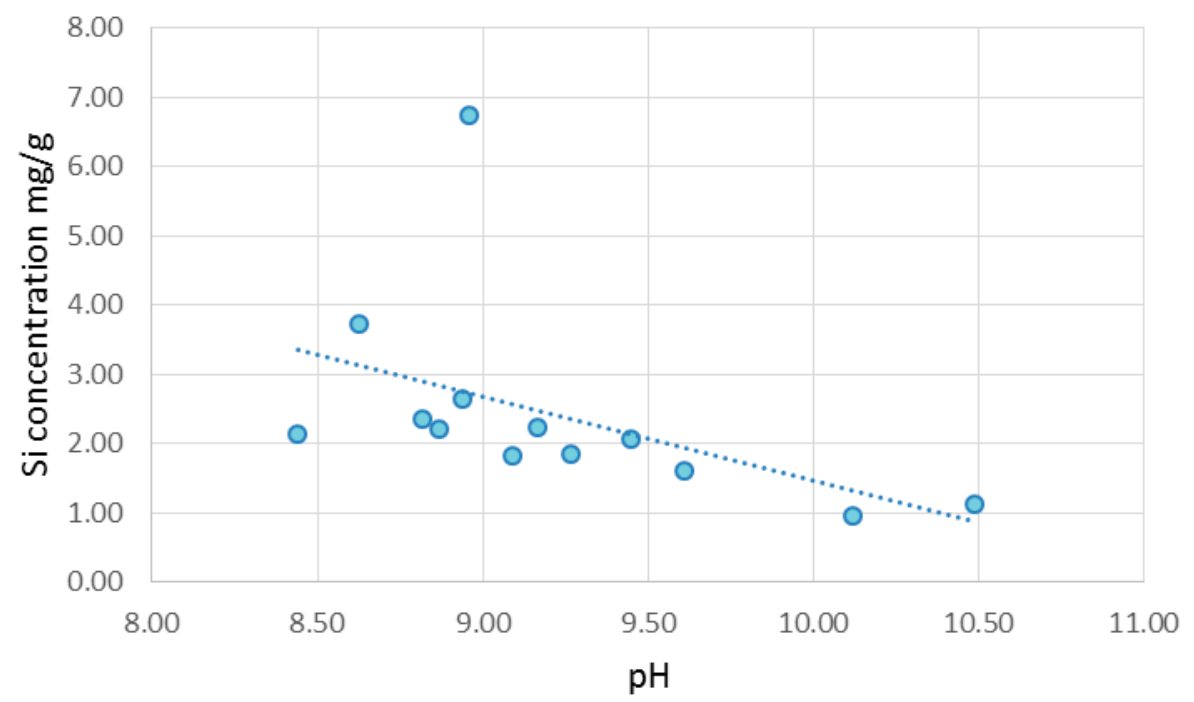

Figure 12. Curves $\mathrm{Si}=\mathrm{f}(\mathrm{pH})$ in potable water $(\mathrm{L})$.

\subsection{Correlation between Sulfate and Leaching Corrosion}

Comparison of the leaching trends of calcium and silicon compounds in magnesium sulfate solution and in potable water via calculated correlation coefficients is presented in Table 9.

Table 9. Correlation coefficient between $\mathrm{Ca}$ and Si leaching based on the type of corrosion, respectively, and $\mathrm{pH}$ values based on the type of corrosion.

\begin{tabular}{ccccccc}
\hline Parameters & \multicolumn{2}{c}{ Ca } & \multicolumn{2}{c}{ Si } & \multicolumn{2}{c}{$\mathbf{H}$} \\
\hline Correlated samples & L/S1 & L/S2 & L/S1 & L/S2 & S1/L & S2/L \\
$R_{\text {xy }}$ & 0.29 & 0.38 & 0.04 & 0.01 & 0.76 & 0.87 \\
\hline
\end{tabular}

Zero-correlation was observed for silicon leaching rates due to magnesium sulfate and potable water. This means that the leaching process and consequent behavior of silicon in leachate of magnesium sulfate differed from the water solution. This confirmed a totally different deterioration of sulfate resisting cement-based concrete regarding silicon leaching when affected by sulfate and leaching corrosion. Based on the low correlation coefficients, this could be concluded for calcium leaching as well. As is known, the deterioration of concrete can be caused by two mechanisms: (i) a dissolution of the cement paste constituents and their subsequent removal from the paste matrix due to its inherent high solubility; and (ii) chemical reactions within the paste, e.g., salt crystallization resulting in the expansion of concrete volume. The leaching process dominated when the concrete sample was subjected to water where the cement hydrates (Portlandite and C-S-H) dissociate, and the reduction in the concentration of $\mathrm{Ca}$ ions in the pore solution led to subsequent dissolution of cement hydrates. On the contrary, when the concrete sample was subjected to a magnesium sulfate solution, besides leaching, the crystallization of sulfate products, e.g., gypsum-Equation (5)—occurred. Sulfate resisting cement is a special type of cement, primarily used in cases with high sulfate corrosion resistance demands; an improved resistance of the concrete samples to sulfate attack is expected, 
compared to Portland-based cements. This is in accordance with other authors, e.g., Hossack [28] and Eštokova [29], who confirm the improved resistance of the concrete samples with the sulfate resisting cement and silica fume to sulfate attack. The finding proved that the performance of sulfate resisting cement-based concrete to sulfate attack was different from that for simple leaching corrosion caused by water.

\section{Conclusions}

The statistical approach was obviously very helpful for the interpretation of the research results. The correlation analysis confirmed different behavior of concrete with sulfate resisting cement when affected by various aggressive media. As assumed, the application of sulfate resisting cement in concrete composites proved to be beneficial in improving the resistance of concrete composites to sulfate attack. However, the improved resistance of concrete when exposed to the influence of sulfuric acid or water leaching was not confirmed. The correlation between Ca leaching and the increase of $\mathrm{pH}$ in leachates was quite a bit lower than expected. The correlation of other parameters analyzed during the experiments (mass changes, compressive strength) is of interest in the future.

Acknowledgments: This research has been carried out with the support of Grant No. 2/0145/15 of the Slovak Grant Agency for Science.

Author Contributions: Adriana Estokova initiated the overall research concept, supervised the research work, and critically revised the content of the paper; Vlasta Ondrejka Harbulakova completed the initial manuscript, and analyzed and partially interpreted measured data; Martina Kovalcikova carried out experiments, managed experimental work and performed measurements of X-ray fluorescence spectrometry.

Conflicts of Interest: The authors declare no conflict of interest.

\section{References}

1. Bertron, A. Mechanisms of degradation of cementitious materials in aggressive aqueous environments. In Performance of Cement-Based Materials in Aggressive Aqueous Environments: State of Art Report Alexander; RILEM TC 211-PAE; Alexander, M., Bertron, A., De Belie, N., Eds.; Springer: Berlin, Germany, 2012; p. 464.

2. Cement and Concrete Association of Australia, Sulfate-Resisting Cement and Concrete. Available online: http://www.imcyc.com/biblioteca/ArchivosPDF/Resistencia\%20a\%20los\%20Sulfatos/Sulfate\% 20resisting\%20cement\%20and\%20concrete.pdf (accessed on 22 June 2017).

3. European Committee for Standardization. EN 206-1: 2002 Concrete. Specification, Performance, Production and Conformity; European Committee for Standardization: Brussels, Belgium, 2002.

4. Agrela, F.; Cabrera, M.; Galvína, A.P.; Barbudo, A.; Ramirez, A. Influence of the sulfate content of recycled aggregates on the properties of cement-treated granular materials using Sulfate-Resistant Portland Cement. Constr. Build. Mater. 2014, 68, 127-134. [CrossRef]

5. Bakharev, T.; Sanjayan, J.G.; Cheng, Y.B. Resistance of alkali-activated slag concrete to acid attack. Cem. Concr. Res. 2003, 33, 1607-1611. [CrossRef]

6. Barbudo, A.; Galvín, A.P.; Agrela, F.; Ayuso, J.; Jiménez, J.R. Correlation analysis between sulfate content and leaching of sulfates in recycled aggregates from construction and demolition wastes. Waste Manag. 2012, 32, 1229-1235. [CrossRef] [PubMed]

7. Pietrucha-Urbanik, K. Failure Prediction in Water Supply System-Current Issues. In Theory and Engineering of Complex Systems and Dependability; Springer: Berlin, Germany, 2015; pp. 351-358.

8. Sulikowski, J.; Kozubal, J. The durability of a concrete sewer pipeline under deterioration by sulfate and chloride corrosion. Procedia Eng. 2016, 153, 698-705. [CrossRef]

9. Mahmoodian, M.; Li, C.Q. Service Life Prediction of Underground Concrete Pipes Subjected to Corrosion. 4th International Conference on Concrete Repair; CRC Press: Boca Raton, FL, USA, 2011.

10. Mahmoodian, M.; Alani, M.A. Multi failure mode assessment of buried concrete pipes subjected to time dependent deterioration using system reliability analysis. J. Fail. Anal. Prev. 2013, 13, 634-642. [CrossRef]

11. Slovak Committee for Standardization. STN 731340 Concrete Constructions. Tests of Corrosion Resistance of Concrete. General Requirements; Slovak Committee for Standardization: Bratislava, Slovakia, 1988. (In Slovak) 
12. Behnood, A.; Tittelboom, K.V.; De Belie, N. Methods for measuring pH in concrete: A review. Constr. Build. Mater. 2016, 105, 176-188. [CrossRef]

13. Kreyszig, E. Advanced Engineering Mathematics, 10th ed.; Wiley: Hoboken, NJ, USA, 2011.

14. Skalny, J.; Marchand, J.; Odler, I. Sulfate. Attack on Concrete; CRC Press: London, UK, 2002; p. 272.

15. Van der Weijden, C.H. Cahiers of Geochemistry Silica I: Silicon Analytical, Physical and Terrestrial Geochemistry; Department of Geosciences-Geochemistry, Utrecht University: Utrecht, The Netherlands, 2008.

16. Zivica, V.; Bajza, A. Acidic attack of cement based materials-A review. Part 1. Principle of acidic attack. Constr. Build. Mater. 2001, 15, 331-340. [CrossRef]

17. Miyamoto, S.; Minagawa, H.; Hisada, M. Deterioration rate of hardened cement caused by high concentrated mixed acid attack. Constr. Build. Mater. 2014, 67, 47-54. [CrossRef]

18. Colombani, J. Measurement of the pure dissolution rate constant of a mineral in water. Geochim. Cosmochim. Acta 2008, 72, 5634-5640. [CrossRef]

19. Gay, H.; Meynet, T.; Colombani, J. Local study of the corrosion kinetics of hardened Portland cement under acid attack. Cem. Concr. Res. 2016, 90, 36-42. [CrossRef]

20. Merida, A.; Kharchi, F. Pozzolan concrete durability on sulfate attack. Procedia. Eng. 2015, 114, $832-837$. [CrossRef]

21. Ondrejka Harbulakova, V.; Estokova, A.; Kovalčíková, M. Study of concrete samples with various contents of slag under sulfates attack using mathematical approach. Czech. J. Civil. Eng. 2016, 2, 116-119.

22. Faucon, P.; Bescop, L.; Adenot, F.; Bonville, P.; Jacquinot, J.F.; Pineau, F.; Felix, B. Leaching of cement: Study of the surface layer. Cem. Concr. Res. 1996, 26, 1707-1715. [CrossRef]

23. Faucon, P.; Adenot, F.; Jacquinot, J.F.; Jorda, M. Long-term behaviour of cement pastes used for nuclear waste disposal: Review of physico-chemical mechanisms of water degradation. Cem. Concr. Res. 1998, 28, 847-857. [CrossRef]

24. Collepardi, M. The New Concrete; Castrette di Villorba: Treviso, Italy, 2006.

25. Hearn, N.; Morley, C.T. Self-sealing property of concrete-Experimental evidence. Mater. Struct. 1997, 30, 404-411. [CrossRef]

26. Haga, K.; Sutou, S.; Hironaga, M.; Tanaka, S.; Nagasaki, S. Effects of porosity on leaching of Ca from hardened ordinary Portland cement paste. Cem. Concr. Res. 2005, 35, 1764-1775. [CrossRef]

27. Rozière, E.; Loukili, A.; El Hachem, R.; Grondin, F. Durability of concrete exposed to leaching and external sulfate attacks. Cem. Concr. Res. 2009, 39, 1188-1198. [CrossRef]

28. Hossack, A.M.; Thomas, M.D.A. Evaluation of the effect of tricalcium aluminate content on the severity of sulfate attack in Portland cement and Portland limestone cement mortars. Cem. Concr. Comp. 2015, 56, 115-120. [CrossRef]

29. Eštokova, A.; Kovalčíková, M.; Luptáková, A.; Praščáková, M. Testing Silica Fume-Based Concrete Composites under Chemical and Microbiological Sulfate Attacks. Materials 2016, 9, 324. [CrossRef] 